\title{
KAJIAN IMPLEMENTASI PROGRAM CSR PERUSAHAAN PERKEBUNAN KELAPA SAWIT KEPADA MASYARAKAT DI KABUPATEN KOTAWARINGIN BARAT
}

\section{(Study of Implementation of CSR Programs Company of Palm Oil Plantation of The Community in West Kotawaringin District)}

\author{
J. Wardie dan E. N. Taufik \\ Fakultas Pertanian, Universitas Palangka Raya \\ Email:jwardie@agb.upr.ac.id \\ Diterima 15 Maret 2017, disetujui 28 Maret 2017
}

\begin{abstract}
ABSTRAK
Tujuan penelitian ini adalah: (1) mengkaji implementasi Program CSR yang dilaksanakan oleh PT. Gunung Sejahtera Ibu Pertiwi (GSIP); dan (2) menganalisis persepsi masyarakat yang bekerja maupun yang tidak bekerja pada perusahaan terhadap implementasi Program CSR yang dilaksanakan oleh PT. GSIP. Penelitian ini dilaksanakan di Desa Pandu Senjaya, Kecamatan Pangkalan Lada, Kabupaten Kotawaringin Barat. Metode penentuan sampel secara acak sederhana (simple random sampling) dengan jumlah sampel sebanyak 60 responden dengan penetapan 30 responden masyarakat yang bekerja pada perusahaan dan 30 responden masyarakat yang tidak bekerja pada perusahaan. Hasil penelitian menunjukkan bahwa implementasi Program CSR perusahaan perkebunan kelapa sawit PT. GSIP kepada masyarakat sebagian besar berfokus pada bantuan bidang ekonomi, sosial budaya dan lingkungan, sedangkan bantuan bidang pendidikan dan kesehatan masih kurang karena perusahaan menganggap bahwa bidang pendidikan dan kesehatan sudah menjadi tanggung jawab pemerintah. Selanjutnya persepsi masyarakat terhadap Program CSR yang dilaksanakan oleh PT. GSIP bahwa masyarakat yang bekerja pada perusahaan berkategori "sesuai" dengan skor 196,40, sedangkan untuk masyarakat yang tidak bekerja pada perusahaan berkategori "raguragu" dengan skor 153,23 . Hal ini dibuktikan pula dengan hasil analisis uji-t yang menunjukkan bahwa terdapat perbedaan signifikan antara persepsi masyarakat yang bekerja pada perusahaan dan masyarakat yang tidak bekerja pada perusahaan terhadap implementasi Program CSR perusahaan. Karena kurangnya pengetahuan dan pemahaman masyarakat tentang kegiatan CSR, sehingga masyarakat menilai bahwa kontribusi dari keberadaan perusahaan dalam implementasi Program CSR belum sepenuhnya sesuai dengan yang diharapkan.
\end{abstract}

Kata Kunci: Program CSR, perusahaan, kelapa sawit

\section{ABSTRACT}

The purpose of this research was to (1) assess the implementation of CSR programs by PT. Gunung Sejahtera Ibu Pertiwi (GSIP); and (2) analyze community perception who working or not working at the company on the implementation of CSR programs by PT. GSIP. This research was conducted in Pandu Senjaya Village, Pangkalan Lada Sub District, West 
Kotawaringin District. Sampling method was done by simple random sampling with a total sample of 60 respondents to the establishment of 30 community respondents who work in company and 30 community respondents who do not work at the company. The results showed that the implementation of CSR programs palm oil plantation company PT. GSIP to the community has largely focused on assistance in economics, socio-culture and the environment, while education and health assistance is still lacking because the company considers that education and health were the government's responsibility. Furthermore, the community perception of CSR programs implemented by PT. GSIP that the people who work at the company categorized as "in accordance" with a score of 196.40, while for people who do not work for company categorized as "doubtful" with a score of 153.23. This was evidenced also by the results of the t-test analysis showed that there were significant differences between the community perception that work for company and people who are not working at the company on the implementation of CSR programs. Due to lack of knowledge and understanding of CSR activities, so that the communities consider that the contribution of the company presence in the implementation of CSR programs not fully in accordance with the expected.

\section{Keywords: CSR Program, Company, Palm Oil}

\section{PENDAHULUAN}

Pertanian merupakan sektor ekonomi utama dan penting dalam menunjang perekonomian nasional.Pertanian dalam arti luas mencakup sub sektor perkebunan, kehutanan, perikanan dan peternakan. Dalam arti sempit, pertanian diartikan sebagai pertanian rakyat berupa usahatani rakyat atau keluarga seperti produk tanaman pangan, palawijadan holtikultura (Mubyarto, 1989). Salah satunya di Kalimantan Tengah dengan adanya sub sektor perkebunan kelapa sawit mempunyai peranan dan kontribusi yang besar dalam perekonomian dan pengembangan wilayah Kalimantan Tengah, baik yang diusahakan sebagaiperkebunan rakyat (petani/pekebun) maupun sebagai perkebunan besar (pengusaha/investor). Kondisi demikian didukung oleh kesesuaian dan ketersediaan lahan yang luas, agroklimat dan ketergantungan petani/pekebun terhadap usaha perkebunan tersebut yang merupakan sumber pendapatan dan kesejahteraan masyarakat yang sudah lama diusahakan.

Perkebunan kelapa sawit di Kalimantan Tengah terus mengalami perkembangan baik dari aspek luas areal maupun produksi. Hingga tahun 2014, luas areal mencapai 1.115.933 Ha dan produksi mencapai 3.158.239Ton. Luas areal dan produksi perkebunan kelapa sawit terbesar di Kalimantan Tengah berturut-turut berada di Kabupaten Kotawaringin Timur, Seruyan dan
Kotawaringin Barat. Luas areal dan produksi inididapatkan baik dari Perkebunan Rakyat (PR), Perkebunan Besar Negara (PBN)maupun Perkebunan Besar Swasta (PBS) (Direktorat Jenderal Perkebunan, 2015).

Pesatnya perkembangan perkebunan kelapa sawit selain memiliki dampak positif juga memiliki dampak negatif. Dampak positifnya adalah dapat meningkatkan pendapatan daerah, penyerapan tenaga kerja, disamping secara khusus dapat meningkatkan pendapatan petani dan pengusaha yang terlibat dalam agroindustri kelapa sawit. Sementara dampak negatif antara lain berpengaruh besar terhadap isu pemanasan global disebabkan karena tanaman kelapa sawit yang merupakan hutan alam monokoltur sangat boros dalam memanfaatkan air tanah sehingga keseimbangan ekologis menjadi terganggu. Adanya dampak negatif ini menjadi alasan berbagai pihak untuk menuduh bahwa perkebunan kelapa sawit sebagai salah satu penyebab pemanasan global. Dampak negatif ini hanya dapat diredam dengan pembangunan perkebunan kelapa sawit yang berkelanjutan dan berwawasan lingkungan (Saragih, 2010).

Pembangunan perkebunan kelapa sawit 
yang berkelanjutan jika dilaksanakan dengan benar dapat meredam isu-isu negatif yang muncul (Kurniawan, 2009). Perkebunan kelapa sawit yang berkelanjutan paling tidak harus memenuhi tiga prinsip utama, yaitu: (1) melindungi dan memperbaiki lingkungan alam (environmentally sound); (2) layak secara ekonomi (economically viable); dan (3) dapat diterima secara sosial (socially accepted). Salah satu upaya untuk menerapkan pembangunan perkebunan kelapa sawit berkelanjutan dari aspek sosial adalah dengan melaksanakan program Corporate Social Responsibility (CSR) oleh perusahaan kepada masyarakat. Harapannya apabila perusahaan melaksanakan program-program CSR dengan baik diharapkan keberlanjutan perusahaan akan terjamin dan selanjutnya dapat menciptakan iklim kehidupan masyarakat menjadi lebih sejahtera dan mandiri. Menurut Wood dan Jones (1995) menyatakan bahwa CSR berpengaruh positif terhadap kinerja perusahaan dan kesejahteraan masyarakat. Sementara peneliti lain menyimpulkan bahwa CSR bersifat netral (McWilliams dan Siegel, 2000), sedangkan Hilman dan Keim (2001), justru menegaskan bahwa implementasi CSR justru membawa kerugian.

Secara teoritis dan konseptual, CSR yang disebut pula dengan tanggung jawab sosial perusahaan dapat dimaknai sebagai tanggung jawab moral suatu perusahaan terhadap berbagai pihak terutama masyarakat di sekitar wilayah perusahaan tersebut. CSR memandang perusahaan sebagai agen moral, dengan atau tanpa aturan hukum, sebuah perusahaan harus menjunjung tinggi prinsip moral dan etis.Dengan demikian, perusahaan yang bekerja dengan mengedepankan prinsip moral dan etis akan memberikan manfaat terbesar bagi masyarakat (Daniri, 2010). Berdasarkan Undang-Undang Nomor 40 Tahun 2007 tentang Perseroan Terbatas menyatakan bahwa dalam implementasi CSR oleh Perseroan yang menjalankan kegiatan usahanya di bidang dan atau berkaitan dengan sumberdaya alam wajib melaksanakan tanggung jawab sosial dan lingkungan.

Demikian pesatnya perkembangan perkebunan kelapa sawit di Kalimantan Tengah khususnya di Kabupaten Kotawaringin Barat memberikan dampak yang luar biasa bagi perekonomian masyarakat baik secara langsung maupun tidak langsung melalui program CSR yang dilaksanakan oleh perusahaan. Salah satu perusahaan perkebunan kelapa sawit besar nasional sebagai Perusahaan Besar Swasta (PBS) di Kabupaten Kotawaringin Barat yang telah melaksanakan program CSR adalah PT. Gunung Sejahtera Ibu Pertiwi (GSIP) yang terletak di wilayah Kecamatan Pangkalan Lada.

Berdasarkan latar belakang di atas, maka tujuan penelitian adalah: (1) mengkaji implementasi Program CSR yang dilaksanakan oleh PT. GSIP; dan (2) menganalisis persepsi masyarakat baik masyarakat yang bekerja maupun yang tidak bekerja pada perusahaan terhadap implementasi Program CSR oleh PT. GSIP.

\section{METODE PENELITIAN}

Metode dasar yang digunakan dalam penelitian ini adalah metode descriptive analysis, yaitu pemecahan masalah aktual

Tabel 1. Kisaran Skor Skala Likert Implementasi Program CSR Perusahaan

\begin{tabular}{crc}
\hline No. & Skor & Implementasi Program CSR Perusahaan \\
\hline 1. & $50-90$ & Sangat Tidak Sesuai \\
2. & $91-130$ & Tidak Sesuai \\
3. & $131-170$ & Ragu-Ragu \\
4. & $171-210$ & Sesuai \\
5. & $211-250$ & Sangat Sesuai \\
\hline
\end{tabular}

Sumber: Istijanto, 2009. Skor yang diolah. 
secara sistematis dari data yang diperoleh dan dikumpulkan untuk selanjutnya disusun, ditabulasi, dianalisis serta dijelaskan baik secara kualitatif dan kuantitatif.

Metode penentuan daerah dan obyek penelitian dilakukan secara purposive sampling (sengaja) dengan alasan karena telah diketahui dari sifat dan karakter daerah tersebut yang dipandang memiliki hubungan erat dengan masalah yang akan diteliti, sehingga sudah cukup relevan dengan tujuan penelitian. Dengan memilih salah satu perusahaan perkebunan kelapa sawit besar nasional sebagai Perusahaan Besar Swasta (PBS) di Kabupaten Kotawaringin Barat yang telah melaksanakan program CSR, yakni PT. GSIP yang terletak di wilayah Kecamatan Pangkalan Lada.

Metode penentuan sampel dilakukan secara acak sederhana (simple random sampling) dengan jumlah sampel sebanyak 60 orang responden dengan penetapan 30 orang responden dipilih dari masyarakat yang bekerja di perusahaan dan 30 orang responden lainnya diambil dari masyarakat yang tidak bekerja pada perusahaan tersebut. Sampel tersebut diambil dari populasi masyarakat setempat yang berdomisilidekatdengan lokasi PT. GSIP yang berada di Desa Pandu Senjaya, Kecamatan Pangkalan Lada, Kabupaten Kotawaringin Barat.

Data yang dikumpulkan dalam penelitian meliputi data primer dan data sekunder. Data primer sebagai data utama diperoleh melalui wawancara langsung terstruktur dengan responden menggunakan kuisioner serta pengamatan langsung pada obyek penelitian. Sementara data sekunder sebagai data penunjang diperoleh dari berbagai dinas atau instansi terkait yang relevan.

Tujuan pertama yaitu mengkaji

Tabel 2. Implementasi Program CSR PT.GSIP

\begin{tabular}{|c|c|c|}
\hline No. & Bidang & Implementasi Program \\
\hline \multirow[t]{2}{*}{1.} & Ekonomi & Bantuan bibit kelapa sawit kepada para petani \\
\hline & & $\begin{array}{l}\text { Pemberdayaan kelompok tani untuk program plasma IGA } \\
\text { (Income Generating Activity) }\end{array}$ \\
\hline \multirow[t]{4}{*}{2.} & Pendidikan & Bantuan dana perbaikan sekolah (SDN) \\
\hline & & Bantuan honor untuk para pengajar TK dan TPA \\
\hline & & Bantuan peralatan sekolahuntuk SMPN1 Pangkalan Lada \\
\hline & & Bantuan peralatan sekolah untukSMAN 1 Pangkalan Lada \\
\hline \multirow[t]{3}{*}{3.} & Kesehatan & Program penyuluhan kesehatan untuk para lansia \\
\hline & & Program penyuluhan untuk ibu-ibu hamil dan menyusui \\
\hline & & Bantuan dana kesehatan untuk balita dan anak-anak \\
\hline \multirow[t]{6}{*}{4.} & Sosial dan Budaya & $\begin{array}{l}\text { Bantuan dana untuk menyelenggarakan kegiatan keagamaan } \\
\text { (Isra Mi'raj) }\end{array}$ \\
\hline & & Bantuan dana untuk kegiatan HUT RI \\
\hline & & Bantuan sembako pada saat bulan ramadhan \\
\hline & & Bantuan dana untuk kegiatan MTQ \\
\hline & & Bantuan pembangunan TPA dan masjid \\
\hline & & Bantuan dana untuk pembangunan GOR \\
\hline \multirow[t]{4}{*}{5 . } & Lingkungan & $\begin{array}{l}\text { Bantuan alat berat untuk memperbaiki jalan dan drainase di } \\
\text { kebun masyarakat }\end{array}$ \\
\hline & & $\begin{array}{l}\text { Bantuan mobil dump truck untuk mengangkut material } \\
\text { perbaikan jalan lingkungan }\end{array}$ \\
\hline & & $\begin{array}{l}\text { Bantuan tanah uruk/laterit untuk menimbun jalan lingkungan } \\
\text { yang rusak }\end{array}$ \\
\hline & & Bantuan dana untuk kebersihan lingkungan \\
\hline
\end{tabular}

Sumber: Kantor Besar PT. GSIP 
Tabel 3. Skor dan Kriteria Persepsi Masyarakat Terhadap Implementasi Program CSR PT. GSIP

\begin{tabular}{crllc}
\hline & & & \multicolumn{2}{c}{ Skor Persepsi } \\
\cline { 3 - 5 } No. & Skor & & $\begin{array}{c}\text { Masyarakat yang } \\
\text { Bekerja pada } \\
\text { Perusahaan }\end{array}$ & $\begin{array}{c}\text { Masyarakat yang } \\
\text { Tidak Bekerja pada } \\
\text { Perusahaan }\end{array}$ \\
\hline 1. & $50-90$ & Sangat tidak sesuai & & \\
2. & $91-130$ & Tidak Sesuai & 196,40 & 153,23 \\
3. & $131-170$ & Ragu-ragu & & \\
4. & $171-210$ & Sesuai & & \\
5. & $211-250$ & Sangat Sesuai & & \\
\hline
\end{tabular}

Sumber: Data Primer yang Diolah.

implementasi Program CSR yang dilaksanakan oleh PT. GSIP, dijelaskan secara deskriptif mendalam. Tujuan kedua yaitu menganalisis persepsi masyarakat terhadap implementasi Program CSR oleh PT. GSIP, dijelaskan dengan teknik skoring menggunakan Skala Likert. Pilihan skala yang digunakan adalah sangat sesuai, sesuai, ragu-ragu, tidak sesuai dan sangat tidak sesuai (Tabel 1). Untuk mendapatkan skor persepsi masyarakat terhadap implementasi Program CSR digunakan 70pernyataan.

Menurut Istijanto (2009), bahwa skala interval adalah skala yang memiliki urutan dan interval (jarak) yang sama antara kategori, dirumuskan sebagai berikut:

$$
\mathrm{i}=\text { Jarak/Jumlah kelas }
$$

Keterangan:

$\mathrm{i} \quad=$ interval kelas

Jarak = nilai data tertinggi dikurangi nilai data terendah
Jumlah kelas $=$ Jumlah interval atau kategori yang ditentukan

Membedakan persepsi antara masyarakat yang bekerja di perusahaan dengan masyarakat yang tidak bekerja pada perusahaan menggunakan analisis t-test (ujit). Uji-t adalah teknik analisis statistik yang digunakan untuk mengetahui ada tidaknya perbedaan nilai rata-rata dari dua kelompok sampel. Selanjutnya nilai t-hitung tersebut dibandingkan dengan nilai t-tabel dengan derajat kebebasan $(\mathrm{dk})=\mathrm{n}_{1}+\mathrm{n}_{2}-2$ dan taraf kesalahan $(\alpha)$ yang digunakan sebesar $5 \%$. Pengujian hipotesis untuk uji-t tersebut, adalah sebagai berikut:

$\mathrm{H}_{0}$ : Tidak terdapat perbedaan persepsi, sikap dan tindakan antara masyarakat yang bekerja di perusahaan dan masyarakat yang tidak bekerja di perusahaan.

$\mathrm{H}_{\mathrm{a}}$ : Terdapat perbedaan persepsi, sikap dan tindakanantaramasyarakat yang bekerja di perusahaan dan masyarakat yang tidak

Tabel 4. Uji Beda Rata-Rata Persepsi Masyarakat yang Bekerja dan yang Tidak Bekerja pada Perusahaan

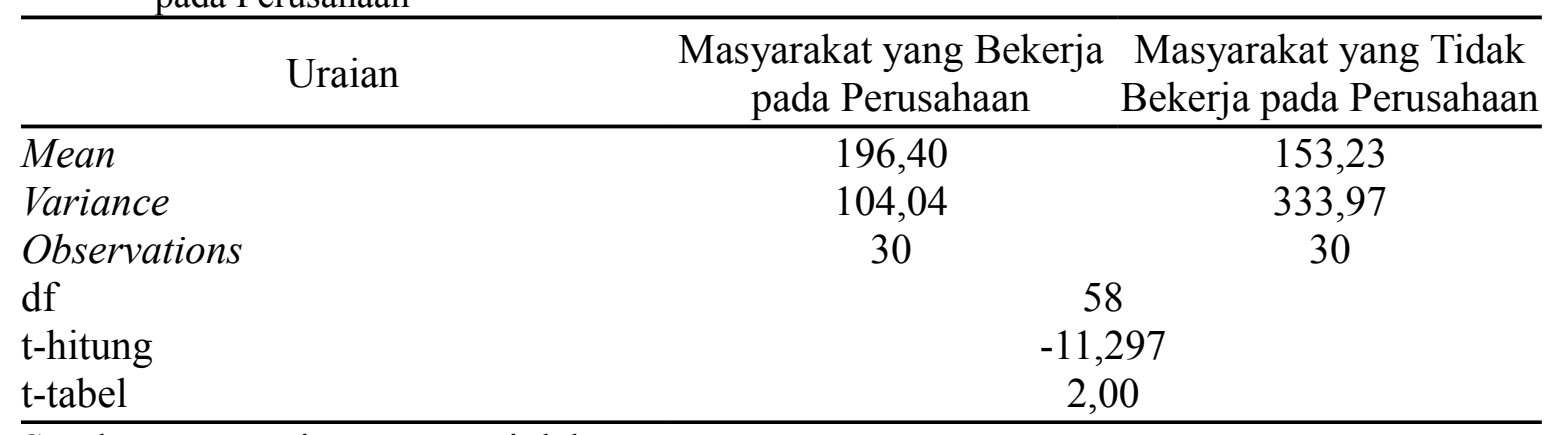

Sumber: Data Primer yang Diolah. 
bekerja di perusahaan.

Keputusannya adalah:

- t-hitung>t-tabel maka $\mathrm{H}_{0}$ ditolak $\left(\mathrm{H}_{\mathrm{a}}\right.$ diterima), artinya terdapat perbedaan secara signifikan

- t-hitung $<$-tabel maka $\mathrm{H} 0$ diterima $\left(\mathrm{H}_{\mathrm{a}}\right.$ ditolak), artinya tidak terdapat perbedaan secara signifikan

\section{HASIL DAN PEMBAHASAN}

\section{Implementasi Program CSR Perusahaan}

Berdasarkan hasil penelitian diperoleh data implementasi Program CSR yang dilaksanakan oleh PT. GSIP seperti terlihat pada Tabel 2. Berdasarkan Tabel 2 diketahui bahwa implementasi Program CSR yang dilaksanakan oleh PT. GSIP pada bidang ekonomi, pendidikan, kesehatan, sosial budaya dan lingkungan belum optimal karena sebagian besar masih berbentuk bantuan. Terlihat bahwa ternyata masih sangat terbatas Program-program CSR perusahaan yang berkaitan dengan pemberdayaan ekonomi masyarakat yang bisa mensejahterakan kehidupan masyarakat.

\section{Persepsi Masyarakat Terhadap Implementasi Program CSR Perusahaan}

Persepsi masyarakat yang dimaksud dalam penelitian ini adalah persepsi masyarakat yang didasari pada pengetahuan/pemahaman, sikap dan tindakan masyarakat terhadap Program CSR yang dilaksanakan oleh PT. GSIP. Berdasarkan persepsi masyarakat terhadap implementasi Program CSR Perusahaan diperoleh kriteria skor seperti terlihat pada Tabel 3.

Berdasarkan Tabel 3 diketahui bahwa persepsi masyarakat yang bekerja pada perusahaan berkategori "sesuai" dengan skor sebesar 196,40. Hal ini berarti bahwa masyarakat menganggap perusahaan sudah bertanggung jawab dan telah melaksanakan kegiatan CSR dengan baik untuk daerahnya. Keberadaan perusahaan bagi masyarakat yang bekerja sangat berperan penting, karena tempat mencari nafkah sehingga bisa memperoleh pendapatan untuk memenuhi kebutuhan ekonomi hidupnya. Tentunya ini bagi masyarakat yang bekerja pada perusahaan memiliki pengetahuan, pemahaman dan pengalaman yang lebih baik tentang keberadaan perusahaan dari pada masyarakat yang tidak bekerja pada perusahaan tersebut.

Sementara persepsi masyarakat yang tidak bekerja pada perusahaan berkategori "raguragu" dengan skor sebesar 153,23 yang berarti bahwa masyarakat memiliki persepsi yang kurang baik terhadap kegiatan CSR yang telah dilaksanakan oleh perusahaan. Hal ini dapat disebabkan karena kurangnya pengetahuan dan pemahaman masyarakat tentang kegiatan CSR, sehingga masyarakat menilai bahwa kontribusi dari keberadaan perusahaan belum sepenuhnya sesuai dengan yang diharapkan. Selama ini bagi masyarakat yang tidak bekerja pada perusahaan tidak begitu mengetahui program CSR yang dilaksanakan karena minimnya sosialisasi dan pengarahan dari pihak perusahaan. Di samping itu, apabila ada pengajuan bantuan kepihak perusahaan jarang terpenuhi karena prosesnya panjang dan rumit sehingga menjadi kendala bagi masyarakat.Kondisi inilah yang terkadang menjadikan masyarakat kurang peduli terhadap keberadaan perusahaan dan menganggap perusahaan kurang memperhatikan dan memberikan kontribusi yang sesuai dengan yang diharapkan.

\section{Komparasi Persepsi Masyarakat yang Bekerja dan yang Tidak Bekerja pada Perusahaan}

Hasil analisis t-test (uji-t) terhadap persepsi masyarakat yang bekerja pada perusahaan dan masyarakat yang tidak bekerja pada perusahaan dapat dilihat seperti pada Tabel 4. Berdasarkan Tabel 4, diketahui bahwa nilai t-hitung $=11,297$ lebih besar dari $t$-tabel $=2,00$ pada taraf signifikan 95\% dengan arah negatif sehingga $\mathrm{H}_{1}$ diterima $\left(\mathrm{H}_{0}\right.$ ditolak), yang berarti bahwa terdapat perbedaan secara signifikan antara persepsi masyarakat yang bekerja pada perusahaan dan masyarakat yang tidak bekerja pada 
perusahaan terhadap implementasi Program CSR perusahaan. Tanda negatif pada t-hitung menunjukkan bahwa persepsi masyarakat yang bekerja pada perusahaan (sesuai) berlawanan arah dengan persepsi masyarakat yang tidak bekerja pada perusahaan (kurang sesuai/ragu-ragu).

\section{SIMPULAN DAN SARAN}

\section{Simpulan}

Berdasarkan hasil analisis dan pembahasan dapat disimpulkan, sebagai berikut:

1. Implementasi Program CSR perusahaan perkebunan kelapa sawit PT. GSIP kepada masyarakat di Desa Pandu Senjaya, Kecamatan Pangkalan Lada Kabupaten Kotawaringin Barat, sebagian besar berfokus pada bantuan bidang ekonomi, sosial budaya dan lingkungan, sedangkan bantuan bidang pendidikan dan kesehatan masih kurang karena perusahaan menganggap bahwa bidang pendidikan dan kesehatan sudah menjadi tanggung jawab pemerintah.

2. Persepsi masyarakat terhadap Program CSR yang dilaksanakan oleh PT. GSIP di Desa Pandu Senjaya, Kecamatan Pangkalan Lada Kabupaten Kotawaringin Barat bahwa masyarakat yang bekerja pada perusahan berkategori "sesuai" dengan skor 196,40, sedangkan untuk masyarakat yang tidak bekerja pada perusahaan berkategori "raguragu dengan skor 153,23. Hal ini dibuktikan pula dengan hasil analisis uji-t yang menunjukkan bahwa terdapat perbedaan signifikan antara persepsi masyarakat yang bekerja pada perusahaan dan masyarakat yang tidak bekerja pada perusahaan terhadap implementasi Program CSR perusahaan. Karena kurangnya pengetahuan dan pemahaman masyarakat tentang kegiatan CSR, sehingga masyarakat menilai bahwa kontribusi dari keberadaan perusahaan dalam implementasi Program CSR belum sepenuhnya sesuai dengan yang diharapkan.

\section{Saran}

Berdasarkan kesimpulan di atas maka dapat disarankan, sebagai berikut:

1. Diharapkan perusahaan untuk masa-masa mendatang lebih memfokuskan dan menambah jumlah program-program bantuan maupun kegiatan CSR khususnya pada bidang pendidikan dan kesehatan yang masih kurang supaya berimbang dengan program bantuan bidang yang lain.

2. Diharapkan sikap dan tindakan masyarakat terhadap implementasi Program CSR yang dilaksanakan perusahaan bisa lebih baik pada masa-masa mendatang. Pemerintah dan pihak terkait lainnya agar bisa memfasilitasi masyarakat untuk lebih berperan aktif terhadap programdan kegiatan CSR yang dilaksanakan oleh perusahaan.

\section{DAFTAR PUSTAKA}

Daniri, M. A. 2010. Standarisasi Tanggung Jawab Sosial Perusahaan. kadinindonesia.or.id/enm/images/dokumen/KA DIN-167-3770-15042009.pdf diakses 25 Februari 2017

Direktorat Jenderal Perkebunan, Kementerian Pertanian. 2015. Statistik Perkebunan Indonesia 2014 - 2016. Kelapa Sawit. Direktorat Jenderal Perkebunan. Jakarta.

Hilman, A.J. and G.D.Keim.2001. Shareholder Value, Stakeholder Management, and Social Issues: What's The Bottom Line? Strategic Management Journal22(2): 125-139.

Istijanto. 2009. Aplikasi Praktis Riset Pemasaran. Gramedia Pustaka Utama. Jakarta.

Kantor Besar PT. Gunung Sejahtera Ibu Pertiwi. 2014. Profil Perusahaan PT. Gunung Sejahtera Ibu Pertiwi. Kantor Besar PT. Gunung Sejahtera Ibu Pertiwi. Pangkalan Lada.

Kurniawan, W. 2009. Urgensi Pembangunan Agroindustri Kelapa Sawit Berkelanjutan Untuk Mengurangi Pemanasan Global. Universitas Trisakti. Jakarta.

McWilliams, A.and D. Siegel. 2000.Corporate Social Responsibility and Financial Performance: Correlation or Misspecification? Strategic Management 
Journal, . 21(5): 603-609.

Mubyarto. 1989. Pengantar Ekonomi

Pertanian. LP3ES. Jakarta.

Saragih. 2010. Implementasi REDD dan Persoalan Kebun Sawit di Indonesia. Jakarta.

Sugiyono. 2009. Statistika untuk Penelitian
PT. Tabita. Bandung.

Wood, D. J. and R.E. Jones. 1995 Stakeholder Mismatching: A Theoretical Problemin Empirical Research on CorporateSocial Performance. International Journal of Organizational Analysis, 3(3): 229 - 267. 